\title{
The mutational burden and oligogenic inheritance in Klippel-Feil syndrome
}

\author{
Ziquan $\mathrm{Li}^{1,2,3}$, Sen Zhao ${ }^{1,2}$, Siyi Cai ${ }^{1}$, Yuanqiang Zhang ${ }^{1,2,3}$, Lianlei Wang ${ }^{1,2,3}$, Yuchen Niü ${ }^{2,4}$, Xiaoxin $\mathrm{Li}^{2,4}$, \\ Jianhua Hu', Jingdan Chen², Shengru Wang ${ }^{1}$, Huizi Wang ${ }^{2}$, Gang Liu' ${ }^{1,2}$, Ye Tian', Zhihong Wü ${ }^{2,4}$, \\ Terry Jianguo Zhang ${ }^{1,2,5}$, DISCO (Deciphering Disorders Involving Scoliosis and COmorbidities) study, \\ Yipeng Wang ${ }^{1,25^{*}}$ and $\mathrm{Nan} \mathrm{Wu}^{1,25^{*}}$
}

\begin{abstract}
Background: Klippel-Feil syndrome (KFS) represents a rare anomaly characterized by congenital fusion of the cervical vertebrae. The underlying molecular etiology remains largely unknown because of the genetic and phenotypic heterogeneity.

Methods: We consecutively recruited a Chinese cohort of 37 patients with KFS. The clinical manifestations and radiological assessments were analyzed and whole-exome sequencing (WES) was performed. Additionally, rare variants in KFS cases and controls were compared using genetic burden analysis.
\end{abstract}

Results: We primarily examined rare variants in five reported genes (GDF6, MEOX1, GDF3, MYO18B and RIPPLY2) associated with KFS and detected three variants of uncertain significance in MYO18B. Based on rare variant burden analysis of 96 candidate genes related to vertebral segmentation defects, we identified BAZ1B as having the highest probability of association with KFS, followed by FREM2, SUFU, VANGL1 and KMT2D. In addition, seven patients were proposed to show potential oligogenic inheritance involving more than one variants in candidate genes, the frequency of which was significantly higher than that in the in-house controls.

Conclusions: Our study presents an exome-sequenced cohort and identifies five novel genes potentially associated with KFS, extending the spectrum of known mutations contributing to this syndrome. Furthermore, the genetic burden analysis provides further evidence for potential oligogenic inheritance of KFS.

Keywords: Klippel-Feil syndrome, Whole-exome sequencing, Genetic burden analysis, Genetic mutational spectrum, Oligogenic inheritance

\section{Background}

Klippel-Feil syndrome (KFS), which was first reported by Maurice Klippel and Andre Feil in 1912, is a complex skeletal disorder characterized by congenital fusion of two or more cervical vertebrae [1]. The incidence of KFS has been estimated as approximately $1 / 40000-1 / 42000$, with a

\footnotetext{
*Correspondence: ypwang@vip.126.com; dr.wunan@pumch.cn 1 Department of Orthopedic Surgery, Peking Union Medical College Hospital, Peking Union Medical College and Chinese Academy of Medical Sciences, Beijing 100730, China

Full list of author information is available at the end of the article
}

slight female predominance by approximately $3: 2[2,3]$. However, the true incidence of KFS may be higher than reported because of heterogeneity in phenotypic expression and a lack of large-scale population screening studies. Based on retrospective studies of cervical computed tomography $(\mathrm{CT})$ in 2917 patients and 131 patients with cervical spondylotic myelopathy, the incidence of KFS may be as high as $1 / 172$ to $5 / 131[4,5]$.

The main etiology of KFS is the impaired development of the cervical vertebrae, which leads to the improper segmentation of the cervical spine. Although KFS can occur

(c) The Author(s). 2020 Open Access This article is licensed under a Creative Commons Attribution 4.0 International License, which permits use, sharing, adaptation, distribution and reproduction in any medium or format, as long as you give appropriate credit to the original author(s) and the source, provide a link to the Creative Commons licence, and indicate if changes were made. The images or other third party material in this article are included in the article's Creative Commons licence, unless indicated otherwise in a credit line to the material. If material is not included in the article's Creative Commons licence and your intended use is not permitted by statutory regulation or exceeds the permitted use, you will need to obtain permission directly from the copyright holder. To view a copy of this licence, visit http://creativecommons.org/licenses/by/4.0/. The Creative Commons Public Domain Dedication waiver (http://creativecommons.org/publicdomain/zero/1.0/) applies to the data made available in this article, unless otherwise stated in a credit line to the data. 
as an isolated malformation, it is often associated with a variety of congenital diseases and other systemic malformations, including scoliosis, Sprengel deformity, urinary malformations, gastrointestinal malformations, hearing impairment, congenital heart defects and various neurological anomalies [1, 6-8]. In addition, congenital fusion deformity of the cervical vertebrae often alters the kinematics of the cervical spine in ways that may accelerate degenerative changes throughout the region. Therefore, patients with KFS usually complain of neck and back pain, respiratory failure, and decreased mobility and may be at risk for death in severe cases due to a lack of early prediction methods.

Recent studies have suggested that the failed vertebral segmentation underlying KFS is caused by defective somitogenesis in the cervical region [9]. Autosomal dominant and recessive inheritance patterns have both been reported in families with KFS. According to Online Mendelian Inheritance in Man (OMIM), mutations in GDF6 (MIM: 601147), MEOX1 (MIM: 600147), GDF3 (MIM: 606522), MYO18B (MIM: 607295) and RIPPLY2 (MIM: 609891) have been associated with KFS [10-15]. Nevertheless, the basis of genetic predisposition to KFS is largely unknown due to the rarity of the disease; only a small number of KFS cases can be explained by the five specific pathogenic genes mentioned above [16]. To further decipher the molecular basis of KFS at the exome level, we herein investigate the molecular findings of WES among a cohort of 37 KFS patients/families, and further analyze rare variants by using a genetic burden method.

\section{Methods}

\section{Cohort collection}

From January 2016 to April 2018, we consecutively recruited 37 patients of Han Chinese ethnicity at Peking Union Medical College Hospital (PUMCH) who had been diagnosed with KFS under DISCO (Deciphering disorders Involving Scoliosis and COmorbidities, DISCO http://discostudy.org/) project. Demographic information, physical examination results, clinical symptoms on presentation, and a detailed medical history were obtained. Radiological assessments including anteroposterior, lateral neutral, and flexion-extension plain radiographs; CT; and magnetic resonance imaging (MRI) were performed on each patient to give a prior clinical diagnosis. Radiographic parameters of interest, such as the segmentation of congenitally fused vertebrae, the Samartzis classification of KFS [8], cervical scoliosis, and sagittal cervical alignment, were also recorded. All radiographic evaluations were conducted by trained spine surgeons, and the clinical review was performed by an alternate observer blinded to the radiographic assessment. None of the investigators were involved in the direct care of the patients.

Prior to study participation, written informed consent was provided by each participant. The study was approved by the Department of Scientific Research and Ethics Committee of PUMCH in China.

Genomic DNA preparation and whole-exome sequencing Genomic DNA for 37 KFS patients (14 cases along with their healthy parents) was extracted from peripheral blood lymphocytes. WES was performed on peripheral blood DNA for all participants. DNA samples were prepared in Illumina libraries and then underwent whole-exome capture with the SureSelect Human All Exon V6 + UTR r2 core design (91 Mb, Agilent, USA), followed by sequencing on the Illumina HiSeq 4000 platform in 150-bp paired-end reads mode (Illumina, San Diego, CA, USA).

\section{Variant annotation and interpretation}

WES data processing was performed with the in-house developed PUMP (Peking Union Medical college hospital Pipeline) [17]. Interpretation of single-nucleotide variants (SNVs) and insertions/deletions (indel variant alleles) were adapted from the American College of Medical Genetics and Genomics (ACMG) guidelines [18]. Computational prediction tools (Genomic Evolutionary Rate Profiling [GERP] [19], Combined Annotation Dependent Depletion [CADD] [20], Sorting Intolerant Form Tolerant [SIFT] [21], Polyphen-2 [22], and MutationTaster [23]) were used to predict the conservation and pathogenicity of candidate variants. All variants were compared to publicly available databases such as the 1000 Genomes Project (http://www.internationalgenome.org/), the NHLBI GO Exome Sequencing Project (ESP) Exome Variant Server (http://evs.gs.washington.edu/EVS/), and the Exome Aggregation Consortium (ExAC) database (http://exac.broadinstitute.org/). The in-house control database consisted of WES data from 534 unrelated Chinese individuals with no apparent skeletal anomalies from DISCO project.

\section{Mutational burden analysis}

A criterion of the internal (combined case and control population) and external (ExAC, and gnomAD) was used to filter for rare genuine variants with a minor allele frequency $(\mathrm{MAF})<0.001$.

After filtering, we performed an initial analysis focusing on variants in reported pathogenic genes (GDF6, MEOX1, GDF3, $M Y O 18 B$ and RIPPLY2) related to KFS. Additionally, 96 genes that were biologically related to vertebral segmentation defects according to previous reports or the Human Phenotype Ontology (HPO; https://hpo.jax.org/), NCBI Gene (https:// ncbi.nlm.nih.gov/gene/) and OMIM (http://omim.org/) databases were added to the candidate gene list (Table S1).

To extend the spectrum of known mutations contributing to KFS, we performed a second-stage analysis to search for exome-wide rare variants in 96 candidate genes related to vertebral segmentation defects using the genetic burden analysis [24]. 


\section{Statistical analysis}

Mean comparison of relevant features was conducted using Student's t-test. One-tailed $P$-values of $<0.05$ were considered statistically significant. Fisher's exact test was used for genetic burden analysis.

\section{Results}

\section{Cohort information}

The study cohort consisted of 37 unrelated KFS patients of Han Chinese ethnicity, including 14 cases with unaffected parents (trios) and 23 singleton cases (Table S2). There were 20 males (54.1\%) and 17 females (45.9\%), with a mean age at diagnosis of $12.6 \pm 5.3$ years. Detailed demographic information is presented in Table 1.

\section{Clinical features and radiographic parameters}

Among the 37 patients with KFS, there was a mean of 2.3 congenital fusion levels (range 1-7), which included various regions of the cervical spine. The most commonly fused

Table 1 Demographic and clinical characteristics of the KFS cohort

\begin{tabular}{|c|c|}
\hline Parameter & KFS cohort $(n=37)$ \\
\hline Age in years, mean (range) & $12.6(5-26)$ \\
\hline \multicolumn{2}{|l|}{ Sex, n (\%) } \\
\hline Men & $20(54.1)$ \\
\hline Women & $17(45.9)$ \\
\hline \multicolumn{2}{|l|}{ Level of fusion, $n(\%)$} \\
\hline $\mathrm{C} 1-\mathrm{C} 2$ & $3(8.1)$ \\
\hline $\mathrm{C} 2-\mathrm{C} 3$ & $15(40.5)$ \\
\hline $\mathrm{C} 3-\mathrm{C} 4$ & $14(37.8)$ \\
\hline $\mathrm{C} 4-\mathrm{C} 5$ & $10(27.0)$ \\
\hline C5-C6 & $13(35.1)$ \\
\hline $\mathrm{C} 6-\mathrm{C} 7$ & $21(56.8)$ \\
\hline $\mathrm{C} 7-\mathrm{T} 1$ & $10(27.0)$ \\
\hline \multicolumn{2}{|l|}{ KFS classification, n (\%) } \\
\hline Type I & $15(40.5)$ \\
\hline Type II & $5(13.5)$ \\
\hline Type III & $17(45.9)$ \\
\hline \multicolumn{2}{|l|}{ Comorbidities, n (\%) } \\
\hline Intraspinal anomalies & $9(24.3)$ \\
\hline Extraskeletal anomalies & $12(32.4)$ \\
\hline \multicolumn{2}{|l|}{ Clinical manifestations, n (\%) } \\
\hline Limited cervical ROM & $17(45.9)$ \\
\hline Short neck & $10(27.0)$ \\
\hline Low posterior hairline & $6(16.2)$ \\
\hline Clinical triad & $4(10.8)$ \\
\hline Torticollis & $4(10.8)$ \\
\hline
\end{tabular}

Abbreviation: ROM range of motion segments were $\mathrm{C} 6-\mathrm{C} 7, \mathrm{C} 2-\mathrm{C} 3$, and $\mathrm{C} 3-\mathrm{C} 4$, which occurred in $56.8 \%, 40.5 \%$, and $37.8 \%$ of the patients, respectively (Fig. 1). According to the KFS classification criteria by Samartzis [8], 15 (40.5\%) patients were Type I, with a single congenitally fused cervical segment; five (13.5\%) patients were Type II, demonstrating multiple noncontiguous congenitally fused cervical segments; and 17 (45.9\%) patients were Type III, showing multiple contiguous congenitally fused cervical segments.

The KFS patients presented with varied intraspinal and extraskeletal anomalies. There were nine patients (24.3\%) manifesting intraspinal deformities, including syringomyelia, diastematomyelia, and tethered cord, and 12 patients (32.4\%) presented with extraskeletal manifestations such as various cardiac defects and malformation of the urinary and digestive systems. KFS has been characterized as a clinical triad of short neck, low posterior hairline, and limited cervical range of motion (ROM). In our cohort, limited cervical ROM was the most common clinical feature (17 patients, $45.9 \%$ ), followed by short neck (10 patients, $27.0 \%)$ and low posterior hairline (six patients, 16.2\%). However, $43.2 \%$ of the patients did not show any typical manifestation of the clinical triad; furthermore, only $10.8 \%$ of the patients showed all three signs in the clinical triad at the same time. Detailed characteristics and radiographic parameters are shown in Table 1.

\section{Variants of known KFS-related genes}

After WES data processing and variant interpretation, we firstly examined filtered rare variants for potential causative variants in five reported genes associated with KFS. As a result, 3 variants were found in $M Y O 18 B$ (Table 2): a splice region mutation (c.2695 + 3A $>$ G) and two missense variants (c.662 T > C and c.5020G > A) were identified in patients CS132, CS1015 and CS1049, respectively. The c. $2695+3 \mathrm{~A}>\mathrm{G}$ variant was found in patient CS132, who was affected by cervical vertebral fusion (C2-C6), short neck, low posterior hairline, limited cervical ROM and protruding ears but no rib or spinal cord abnormalities.

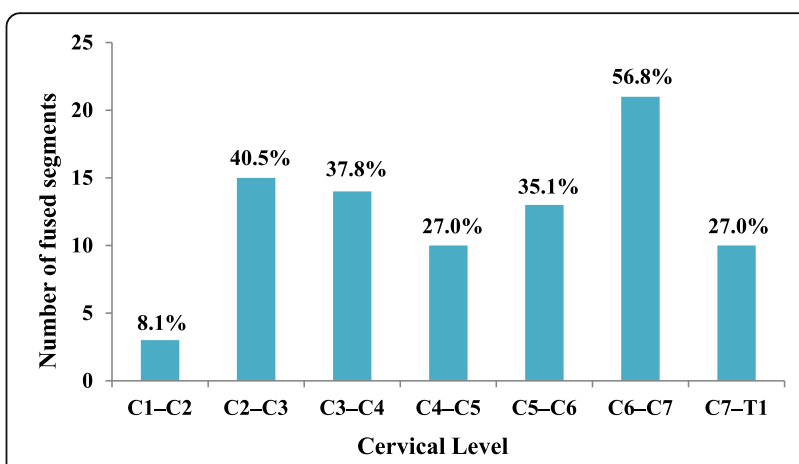

Fig. 1 The number and prevalence (\%) of fused segments in our KFS cohort. The figure illustrates the distribution of fused cervical levels among the cervical segments 
Table 2 MYO18B variants and clinical features of patients

\begin{tabular}{|c|c|c|c|}
\hline Identifier & CS132 & CS1015 & CS1049 \\
\hline Sex/age (years) at diagnosis & $F / 12$ & $M / 5$ & $\mathrm{~F} / 7$ \\
\hline \multicolumn{4}{|l|}{ Mutation information } \\
\hline Variant type & Splice region & Missense & Missense \\
\hline Zygosity & Heterozygous & Heterozygous & Heterozygous \\
\hline Chr_Position & 22_26219648 & 22_26164545 & 22_26299670 \\
\hline Variant nomenclature & c. $2695+3 A>G$ & c.662 T > C (p.Leu221Pro) & c.5020G > A (p.Gly1674Arg) \\
\hline EXAC AF & 0.000017 & 0.000034 & 0.000013 \\
\hline gnomAD AF & Novel & 0.0000324 & 0.00003232 \\
\hline In-house exome database AF & 0.0029 & Novel & Novel \\
\hline \multicolumn{4}{|l|}{ Clinical features } \\
\hline Fused levels & $\mathrm{C} 2-\mathrm{C} 6$ & $\mathrm{C} 6-\mathrm{C} 7$ & $\mathrm{C} 1-\mathrm{T} 1$ \\
\hline Comorbidities & Protruding ears & Tetralogy of Fallot, congenital solitary kidney & Patent foramen ovale \\
\hline Clinical manifestations & Clinical triad & None & Clinical triad, torticollis \\
\hline Classification & Type III & Type I & Type III \\
\hline Other vertebral and costal abnormalities & None & None & $\begin{array}{l}\text { Rib fusion } \\
\text { Sacrococcygeal agenesis }\end{array}$ \\
\hline
\end{tabular}

Moreover, congenital cervical fusions combined with congenital heart disease were found in both CS1015 and CS1049. The variant c.662 T > C (p. Leu221Pro) in exon 4 was identified in proband CS1015, who presented with a single vertebral fusion level at $\mathrm{C6}-\mathrm{C} 7$ and no severe clinical manifestations in the cervical spine. However, the c.5020G > A (p. Gly1674Arg) variant was observed in exon 31 from patient CS1049, who had long-segment cervical fusion (C1-T1), a prominent clinical triad and torticollis.

MYO18B, an unconventional class XVIII myosin, is mainly expressed in human cardiac and skeletal muscle and plays putative roles in diverse human syndromes and cellular processes [25]. Consistent with the reported phenotypes of myocardial defects in $M Y O 18 B$-deficient mice, two of our patients suffered from cardiac deformities. A homozygous nonsense mutation in $M Y O 18 B$ (c.6905C > A: p.S2302*) was identified in two unrelated patients who came from consanguineous families and exhibited a similar phenotype of KFS, myopathy, short stature, and facial dysmorphism [14], and moreover, compound heterozygous frameshift variants (c.6768delG: p.Leu2257SerfsTer16 and c.6660_6670delATTAGAACCTG: p.Arg2220SerfsTer74) in MYO18B were reported in a medulloblastoma patient with a previous diagnosis of KFS [26]; nonetheless, there are still no reports on pathogenic missense variants in $M Y O 18 B$ associated with KFS due to the limited sample size.

\section{Genetic burden analysis of candidate genes related to vertebral segmentation defects}

Based on the rare variant filtering of the candidate gene list (Table S1), we found that the average number of rare variants per individual in the KFS cohort $(n=33)$ was significantly higher than that in control individuals $(n=$ 202) $(p<0.0001)$ (Table S3), which suggests that the candidate genes were relevant to the KFS etiology.

Furthermore, in the gene-based burden analysis, we compared the exome-wide frequency of rare coding variants for each candidate gene in KFS cases and controls. Among the genes associated with the KFS cohort compared to controls, the five with the lowest $P$-values were $B A Z 1 B(P=0.000$ 00002), FREM2 $(P=0.0003)$, SUFU $(P=0.0004)$, VANGL1 $(P=0.0072)$ and $K M T 2 D(P=0.0214)$ (Table 3$)$.

\section{Variants identified in potential KFS-associated genes}

We identified three qualified variants of $B A Z 1 B$ from three patients. The in-frame insertion variant c.3804 3821dupGGAGGAGGAGGAAGAAGA (p. Glu1268_ Glu1273dup) in $B A Z 1 B$ was identified in CS63. The patient was a 6-year-old female with complaints of restricted neck motion and torticollis. Radiological evaluation detected fusion of the cervical vertebrae at C6-T1, scoliosis, diastematomyelia, syringomyelia, and polycystic kidney disease. $B A Z 1 B$ encodes a member of a bromodomain protein family that is involved in chromatin-dependent regulation of transcription. Deletion of this gene has been reported in Williams-Beuren syndrome (WBS), a developmental disorder featuring multiple skeletal deformities such as scoliosis, hallux valgus, little-finger clinodactyly, fusion of the cervical spine and Chiari I malformation [27]. Although $B A Z 1 B$ has no previously identified connection to KFS, the present finding may represent a novel disease association. In addition, two other rare missense variants of $B A Z 1 B$, namely, c.527A > G (p.Lys176Arg) and c.1364G > A (p.Arg455Gln), were also identified. Both patients suffered 
Table 3 Genetic burden analysis for rare variant frequencies in KFS cases and controls

\begin{tabular}{llllll}
\hline & KFS cases $(\mathrm{n})$ & Variant alleles & Control subjects $(\mathrm{n})$ & Variant alleles & $p$-value \\
\hline BAZ1B & 37 & 3 & 534 & 1 & 0.00000002 \\
FREM2 & 37 & 3 & 534 & 5 & 0.0003 \\
SUFU & 37 & 2 & 534 & 2 & 0.0004 \\
VANGL1 & 37 & 2 & 534 & 4 & 0.0072 \\
KMT2D & 37 & 3 & 534 & 11 & 0.0214 \\
\hline
\end{tabular}

from single-segment cervical fusion and only mild clinical manifestations, despite multiple intraspinal deformities such as diastematomyelia, tethered cord and syringomyelia.

A heterozygous missense variant of c.8479C $>$ T (p. Arg2827Cys) in the FREM2 gene was detected, with an ExAC allele frequency of 0.000016 . This variant was predicted as pathogenic by the functional prediction programs SIFT, Polyphen-2 and MutationTaster, with a GERP score of 3.79 and a CADD score of 18.07. It was reported that homozygosity for a splice site mutation in the FREM2 gene was associated with Fraser syndrome and that compound heterozygosity for a missense mutation was related to cryptophthalmos [28, 29].

Three other rare heterozygous missense variants c.13364G > A (p.Arg4455His), c.3074C > T (p.Ser1025Leu), c.8939C > T (p.Ala2980Val) in KMT2D were identified in
CS488, CS1162 and CS1210. These three patients suffered from multiple contiguous fused cervical levels: $\mathrm{C} 2-\mathrm{C} 7, \mathrm{C} 2-$ $\mathrm{C} 7$, and $\mathrm{C} 5-\mathrm{T} 1$, respectively. The protein encoded by $K M T 2 D$ has been shown to be a transcriptional regulator of the beta-globin and estrogen receptor genes and is reported to be a cause of Kabuki syndrome [30-32]. Therefore, the significant association of KMT2D with KFS involving multiple fused segments (Type III) may represent an expansion of the known phenotype associated with this gene.

Two other rare missense variants in FREM2 and variants of the associated genes VANGL1 and SUFU are shown in Table 4.

\section{Potential oligogenic inheritance}

Among qualified variants, seven patients (18.9\%) showed potential involvement of multiple associated variations

Table 4 Information on rare variants of five novel associated genes

\begin{tabular}{|c|c|c|c|c|c|c|c|c|c|}
\hline Patient & $\begin{array}{l}\text { Gene } \\
\text { symbol }\end{array}$ & Variant type & Zygosity & Chr_Position & $\begin{array}{l}\text { Ref } \\
\text { transcript }\end{array}$ & Variant nomenclature & $\begin{array}{l}\text { GERP++ } \\
\text { score }\end{array}$ & $\begin{array}{l}\text { CADD } \\
\text { score }\end{array}$ & $\begin{array}{l}\text { ExAC } \\
\text { AF-total }\end{array}$ \\
\hline $\mathrm{CS63}$ & $B A Z 1 B$ & $\begin{array}{l}\text { In-frame } \\
\text { insertion }\end{array}$ & Het & 7_72861616 & $\begin{array}{l}N_{-} \\
032408.3\end{array}$ & $\begin{array}{l}\text { c.3804_3821dupGGAGGAGGAGGAAGAAGA } \\
\text { (p.Glu1268_Glu1273dup) }\end{array}$ & - & - & 0.000016 \\
\hline CS216 & $B A Z 1 B$ & Missense & Het & 7_72912871 & $\begin{array}{l}\mathrm{NM}_{-} \\
032408.3\end{array}$ & c.527A > G (p.Lys176Arg) & 5.26 & 17.03 & 0.0000082 \\
\hline CS519 & $B A Z 1 B$ & Missense & Het & 7_72892427 & $\begin{array}{l}\mathrm{NM}_{-} \\
032408.3\end{array}$ & c.1364G > A (p.Arg455Gln) & 5.56 & 11.17 & 0.000016 \\
\hline CS193 & FREM2 & Missense & Het & 13_39452441 & $\begin{array}{l}N_{2} M_{-} \\
207361.4\end{array}$ & c.8842 T > C (p.Tyr2948His) & 0.572 & 5.468 & 0.000033 \\
\hline CS1049 & FREM2 & Missense & Het & 13_39450454 & $\mathrm{NM}_{207361.4}$ & c.8479C > T (p.Arg2827Cys) & 3.79 & 18.07 & 0.000016 \\
\hline OS1056 & FREM2 & Missense & Het & 13_39424205 & $\begin{array}{l}N_{2} \\
207361.4\end{array}$ & c.6410A > T (p.Tyr2137Phe) & 5.79 & 17.11 & 0.0000083 \\
\hline CS488 & KMT2D & Missense & Het & 12_49425124 & $\begin{array}{l}N_{-} M_{-} \\
003482.3\end{array}$ & c.13364G > A (p.Arg4455His) & 5.57 & 13.45 & 0.000058 \\
\hline CS1162 & KMT2D & Missense & Het & 12_49444297 & $\begin{array}{l}\mathrm{NM}_{-} \\
003482.3\end{array}$ & c.3074C > T (p.Ser1025Leu) & 3.4 & 6.896 & 0.000059 \\
\hline CS1210 & KMT2D & Missense & Het & 12_49432200 & $\begin{array}{l}N_{-} M_{-} \\
003482.3\end{array}$ & c.8939C > T (p.Ala2980Val) & 2.77 & 11.24 & 0.000017 \\
\hline CS63 & SUFU & Missense & Het & $\begin{array}{l}10 \\
104375107\end{array}$ & $\mathrm{NM}_{016169.3}$ & c.1105G > A (p.Val369lle) & 5.21 & 12.54 & 0.000091 \\
\hline CS132 & SUFU & Splice region & Het & $\begin{array}{l}10 \\
104375165\end{array}$ & $\mathrm{NM}_{016169.3}$ & c. $1157+6 C>T$ & - & - & 0.000033 \\
\hline CS1130 & VANGL1 & Synonymous & Het & 1_116206326 & $\begin{array}{l}N_{138959.2} \\
-\end{array}$ & c. $249 \mathrm{G}>$ A (p.Ser83=) & - & - & 0.00012 \\
\hline CS927 & VANGL1 & Missense & Het & 1_116227985 & $\begin{array}{l}N_{1} \\
138959.2\end{array}$ & c.1151C > G (p.Pro384Arg) & 5.44 & 25.8 & 0.0000083 \\
\hline
\end{tabular}


Table 5 Potential oligogenic inheritance in seven KFS patients

\begin{tabular}{|c|c|c|c|}
\hline Patient & Gene symbol & Variant type & Variant nomenclature \\
\hline \multirow[t]{4}{*}{ CS63 } & $B A Z 1 B$ & In-frame insertion & c.3804_3821dupGGAGGAGGAGGAAGAAGA (p.Glu1268_Glu1273dup) \\
\hline & GRIP1 & Splice acceptor & c. 1043-1G > A \\
\hline & SUFU & Missense & c.1105G > A (p.Val369lle) \\
\hline & TBX6 & Missense & c.499C > T (p.Arg167Cys) \\
\hline \multirow[t]{3}{*}{ CS132 } & MYO18B & Splice region & c. $2695+3 A>G$ \\
\hline & SUFU & Splice region & $C .1157+6 C>T$ \\
\hline & WNT7A & Missense & c.83C > T (p.Ser28Leu) \\
\hline \multirow[t]{3}{*}{ CS587 } & FUZ & Missense & c.819C > A (p.Asp273Glu) \\
\hline & MAP3K7 & Missense & c.1115G > A (p.Arg372His) \\
\hline & $P O R$ & Missense & c.1798C > T (p.Arg600Trp) \\
\hline \multirow[t]{2}{*}{ CS676 } & CHD7 & Synonymous & c.4008C > T (p.lle1336=) \\
\hline & FRAS1 & Missense & c.7423G > A (p.Glu2475Lys) \\
\hline \multirow[t]{2}{*}{ CS519 } & $B A Z 1 B$ & Missense & c.1364G > A (p.Arg455Gln) \\
\hline & COG1 & Missense & c.739C > T (p.His247Tyr) \\
\hline \multirow[t]{3}{*}{ CS1015 } & ANKRD11 & Missense & c.6067G > T (p.Ala2023Ser) \\
\hline & HOXD13 & Missense & c.814G > A (p.Val272lle) \\
\hline & MYO18B & Missense & c.662 T > C (p.Leu221Pro) \\
\hline \multirow[t]{2}{*}{ CS1049 } & FREM2 & Missense & c.8479C > T (p.Arg2827Cys) \\
\hline & MYO18B & Missense & c.5020G > A (p.Gly1674Arg) \\
\hline
\end{tabular}

in different genes (Table 5), which represented an increased ratio compared with that of the in-house controls (30/534) $(P=0.00148)$. Specifically, an in-frame insertion variant of $B A Z 1 B$, a splice acceptor variant of GRIP1, and two missense variants of SUFU and TBX6 were detected in patient CS63, and there were three patients carrying three variants in different candidate genes and another three patients carrying two variants in different genes. Additionally, MYO18B, SUFU, and BAZ1B, mutations of which were probably causative of KFS, were identified in two or more patients. This finding suggests the possibility of an oligogenic pathogenesis pattern.

\section{Discussion}

KFS is a relatively rare disorder characterized by congenital synostosis of the cervical vertebrae because of a segmentation or formation defect. However, articles related to KFS are limited and mostly use individual case reports or small case series. Therefore, the 37-patient cohort in the current study is a relatively large reported KFS cohort for assessing clinical features and radiologic parameters and for identifying molecular findings by WES.

The clinical manifestations of KFS show substantial heterogeneity, and the typical clinical features are defined as a triad of short neck, low posterior hairline, and limited neck ROM. However, as found in our case cohort, the complete clinical triad was noted in only $10.8 \%$ of patients. Moreover, $43.2 \%$ of our KFS cohort did not present with any of these findings, which was consistent with a singlecenter retrospective study of 31 patients by Samartzis in 2016 [33]. Further analysis with imaging data demonstrated that $73.3 \%$ of the 15 Type I KFS patients exhibited none of the three clinical triad signs; on the other hand, all four patients presenting with clinical triad findings were considered Type III. KFS patients with multiple contiguous congenitally fused cervical levels are confirmed to be at a significantly increased risk of severe clinical manifestations. As such, proper precautionary measures and close follow-up should be suggested in KFS patients, especially those regarded as Type III.

Although the pathogenesis of the developmental defect underlying KFS is thought to be attributable to the paraxial mesoderm and somites at the embryonic stage, which may result from mutations or disruptions in genes regulating segmentation and resegmentation, the underlying etiology of KFS is still inconclusive [2, 34, 35]. Previous studies suggested that mutations in GDF6 [10, 36] and GDF3 [13] were associated with autosomal dominant KFS. In addition, a truncating mutation in MEOX1 [11, $12,37]$ and a homozygous nonsense mutation in $M Y O 18 B$ $[14,38]$ were identified in autosomal recessive KFS families. Using WES, a homozygous frameshift mutation (c.299delT: p. L100fs) in RIPPLY2 was confirmed as a novel gene for autosomal recessive KFS in a consanguineous family $[15,39]$. In this study, by performing WES on 37 KFS patients, we investigated rare variants in known 
KFS-related genes, and only three variants in $M Y O 18 B$ were detected. However, these novel missense variants in $M Y O 18 B$ are still of uncertain significance. Therefore, the etiology of the disease has not been fully explained by the reported mutations associated with KFS.

Gene-based burden analysis has grown into a new approach for discovering genes associated with rare disorders, in which the mutational burden of qualifying variants is compared between case and control subjects for each gene $[40,41]$. As a result, we identified five genes $(B A Z 1 B$, FREM2, VANGL1, SUFU and KMT2D) with a significantly increased number of predicted damaging exonic variants in the KFS cohort compared with in-house controls in genetic burden analysis. Pathogenic mutations in $B A Z 1 B$ are frequently associated with Williams-Beuren syndrome, which is a neurodevelopmental disorder characterized by craniofacial dysmorphology, cardiovascular problems, renal abnormalities and musculoskeletal abnormalities [27]. Mutations in VANGL1 have previously been associated only with caudal regression syndrome, a rare neural tube defect disease with an abnormal development of the vertebral column and spinal cord. Furthermore, a rare case report described a female patient with Williams-Beuren syndrome combined with caudal regression syndrome. In addition to the typical developmental abnormalities, fusion of L4-5 and sacrococcygeal agenesis were reported based on radiologic evaluation [42]. These data reinforced the probability of an important role for $B A Z 1 B$ and VANGL1 in the pathogenesis of congenital vertebral fusion, broadening the spectrum of known disorders related to these genes.

Missense variants and splice region mutations of SUFU were identified in two patients. Aside from the common Joubert syndrome phenotypes such as hyperpnoea, eye movements and developmental retardation, calvarial bone formation has been linked to SUFU mutations. Although SUFU has not been associated with congenital cervical fusion deformities, it has been reported that SUFU is the main negative regulator of the Sonic Hedgehog pathway, and ablation of SUFU inhibits the proliferation of osteoprogenitor cells, resulting in failure of calvarial bone formation [43, 44]. Nevertheless, the relationship between SUFU and the KFS phenotype still requires further study.

Oligogenic inheritance, characterized by the concurrent effect of two or more distinct genes on the resulting phenotype, was subsequently confirmed to apply to other skeletal deformities such as arthrogryposis [45]. Based on the results from previous studies and our findings, the etiology of congenital cervical fusion is unlikely to be fully explained by a monogenetic model for a fraction of patients. It is possible that mutation burden and combinatorial effects of rare variants in genes that interact genetically in the same biological pathways modify the phenotype of KFS due to synergistic or counteracting effects.

\section{Conclusions}

In conclusion, our study presents clinical features and WES findings from a large cohort of KFS patients to date. Beyond identifying known candidate genes, our analysis highlights five novel rare variants associated with cervical congenital fusion among KFS patients through genetic burden analysis. These results indicate a highly significant enrichment of predicted damaging genes and the potential oligogenic inheritance of KFS.

\section{Supplementary information}

Supplementary information accompanies this paper at https://doi.org/10. 1186/s12891-020-03229-X.

Additional file 1 Table S1. List of candidate genes associated with vertebral segmentation defects as well as related diseases Table S2. Participants' demographic and clinical characteristics Table S3. Gene burden analysis of rare variants of candidate genes between KFS cases and in-house controls

\section{Abbreviations}

KFS: Klippel-Feil syndrome; WES: Whole-exome sequencing; ROM: Range of motion; WBS: Williams-Beuren syndrome; MRI: Magnetic resonance imaging; CT: Computed tomography; OMIM: Online Mendelian Inheritance in Man; SNVs: Single-nucleotide variants; ACMG: American College of Medical Genetics and Genomics; GERP: Genomic Evolutionary Rate Profiling; CADD: Combined Annotation Dependent Depletion; SIFT: Sorting Intolerant Form Tolerant; ESP: Exome Sequencing Project; ExAC: Exome Aggregation Consortium

\section{Acknowledgments}

The author would like to thank the patients and their family members for their help and informed consent.

\section{Authors' contributions}

$\mathrm{ZL}, \mathrm{SZ}, \mathrm{SC}, \mathrm{YZ}$, and LW performed the study. YN, HW, JH, SW, GL, XL and JC participated in the experiment and data collection/interpretation for the study. YT, ZW, and JZ conceived of the study and participated in its design. YW and NW were responsible for coordination, data collection/interpretation and proofreading of the final manuscript. The final version of the manuscript has been reviewed and approved by all the authors for publication.

\section{Funding}

This research was funded in part by the National Natural Science Foundation of China (81822030 to N.W., 81572097 and 81871746 to Y.W., 81772299 and 81930068 to Z.W., 81672123 and 81972037 to J.Z., 81902178 to S.W., 81902271 to G.L.), Beijing Natural Science Foundation (7191007 to Z.W.), CAMS Initiative Fund for Medical Sciences (2016-12M-3-003 to N.W., 2016I2M-2-006 and 2017-12M-2-001 to Z.W.), National Key Research and Development Program of China (No. 2018 YFC0910506 to N.W. and Z.W.).

\section{Availability of data and materials}

All data analyzed during this study is included in this published article. The raw data is available at the corresponding author upon request.

Ethics approval and consent to participate

All subjects provided informed consent to take part in the study. Written informed consent was obtained from the parents/guardians of the minors included in this study (minors are considered anyone under the age of 16). The study was approved by the Department of Scientific Research and Ethics Committee of PUMCH in China.

Consent for publication

Not applicable.

Competing interests

The authors declare that they have no competing interests. 


\section{Author details}

'Department of Orthopedic Surgery, Peking Union Medical College Hospital, Peking Union Medical College and Chinese Academy of Medical Sciences, Beijing 100730, China. ${ }^{2}$ Beijing Key Laboratory for Genetic Research of Skeletal Deformity, Beijing 100730, China. ${ }^{3}$ Graduate School of Peking Union Medical College, Beijing 100005, China. ${ }^{4}$ Medical Research Center, Peking Union Medical College Hospital, Peking Union Medical College and Chinese Academy of Medical Sciences, Beijing 100730, China. ${ }^{5}$ Key Laboratory of Big Data for Spinal Deformities, Chinese Academy of Medical Sciences, Beijing 100730, China.

\section{Received: 29 January 2020 Accepted: 23 March 2020} Published online: 11 April 2020

\section{References}

1. Hensinger R, Lang J, MacEwen G. Klippel-Feil syndrome; a constellation of associated anomalies. J Bone Joint Surg Am. 1974;56:1246-53.

2. Tracy MR, Dormans JP, Kusumi K. Klippel-Feil Syndrome. Clin Orthop Relat Res. 2004;424:183-90.

3. Brown MW, Templeton AW, Hodges FJ. The incidence of acquired and congenital fusions in the cervical spine. Am J Roentgenol Radium Ther Nuc Med. 1964;92:1255-9.

4. Gruber J, Saleh A, Bakhsh W, Rubery PT, Mesfin A. The prevalence of KlippelFeil syndrome: a computed tomography-based analysis of 2,917 patients. Spine Deformity. 2018;6:448-53.

5. Nouri A, Tetreault L, Zamorano JJ, Mohanty CB, Fehlings MG. Prevalence of Klippel-Feil syndrome in a surgical series of patients with cervical Spondylotic myelopathy: analysis of the prospective, multicenter AOSpine North America study. Global Spine J. 2015;5:294-9.

6. Xue $X$, Shen J, Zhang J, Tian Y, Zhao H, Wang Y, et al. Klippel-Feil syndrome in congenital scoliosis. Spine (Phila Pa 1976). 2014;39:E1353-8.

7. Mesfin A, Bakhsh WR, Chuntarapas T, Riew KD. Cervical scoliosis: clinical and radiographic outcomes. Global Spine J. 2016;6:7-13.

8. Samartzis DD, Herman J, Lubicky JP, Shen FH. Classification of congenitally fused cervical patterns in Klippel-Feil patients: epidemiology and role in the development of cervical spine-related symptoms. Spine. 2006;31:E798-804.

9. Cho W, Shepard N, Arlet V. The etiology of congenital scoliosis: genetic vs. environmental-a report of three monozygotic twin cases. European spine journal : official publication of the European spine society, the European spinal deformity society, and the European section of the cervical spine research. Society. 2018:27:533-7.

10. Tassabehji M, Fang ZM, Hilton EN, McGaughran J, Zhao Z, de Bock CE, et al. Mutations in GDF6 are associated with vertebral segmentation defects in Klippel-Feil syndrome. Hum Mutat. 2008;29:1017-27.

11. Bayrakli F, Guclu B, Yakicier C, Balaban H, Kartal U, Erguner B, et al. Mutation in MEOX1 gene causes a recessive Klippel-Feil syndrome subtype. BMC Genet. 2013;14:95.

12. Mohamed JY, Faqeih E, Alsiddiky A, Alshammari MJ, Ibrahim NA, Alkuraya FS. Mutations in MEOX1, encoding mesenchyme homeobox 1, cause Klippel-Feil anomaly. Am J Hum Genet. 2013:92:157-61.

13. Ye M, Berry-Wynne KM, Asai-Coakwell M, Sundaresan P, Footz T, French CR, et al. Mutation of the bone morphogenetic protein GDF3 causes ocular and skeletal anomalies. Hum Mol Genet. 2010;19:287-98.

14. Alazami AM, Kentab AY, Faqeih E, Mohamed JY, Alkhalidi H, Hijazi H, et al. A novel syndrome of Klippel-Feil anomaly, myopathy, and characteristic facies is linked to a null mutation in MYO18B. J Med Genet. 2015;52:400-4.

15. Karaca E, Yuregir OO, Bozdogan ST, Aslan H, Pehlivan D, Jhangiani SN, et al. Rare variants in the notch signaling pathway describe a novel type of autosomal recessive Klippel-Feil syndrome. Am J Med Genet Part A. 2015; 167a:2795-9.

16. Chacón-Camacho O, Camarillo-Blancarte L, Pelaez-González H, Mendiola J, Zenteno JC. Klippel-Feil syndrome associated with situs inversus: description of a new case and exclusion of GDF1, GDF3 and GDF6 as causal genes. Eur J Med Genet. 2012:55:414-7.

17. Wang K, Zhao S, Liu B, Zhang Q, Li Y, Liu J, et al. Perturbations of BMP/TGF$\beta$ and VEGFNEGFR signalling pathways in non-syndromic sporadic brain arteriovenous malformations (BAVM). J Med Genet. 2018;55:675-84.

18. Richards S, Aziz N, Bale S, Bick D, Das S, Gastier-Foster J, et al. Standards and guidelines for the interpretation of sequence variants: a joint consensus recommendation of the American College of Medical Genetics and Genomics and the Association for Molecular Pathology. Genet Med. 2015;17:405-24.
19. Davydov EV, Goode DL, Sirota M, Cooper GM, Sidow A, Batzoglou S Identifying a high fraction of the human genome to be under selective constraint using GERP++. PLoS Comput Biol. 2010;6:e1001025.

20. Kircher M, Witten DM, Jain P, O'Roak BJ, Cooper GM, Shendure J. A general framework for estimating the relative pathogenicity of human genetic variants. Nat Genet. 2014:46:310-5.

21. Vaser R, Adusumalli S, Leng SN, Sikic M, Ng PC. SIFT missense predictions for genomes. Nat Protoc. 2016;11:1-9.

22. Adzhubei IA, Schmidt S, Peshkin L, Ramensky VE, Gerasimova A, Bork P, et al. A method and server for predicting damaging missense mutations. Nat Methods. 2010;7:248-9.

23. Schwarz JM, Cooper DN, Schuelke M, Seelow D. MutationTaster2: mutation prediction for the deep-sequencing age. Nat Methods. 2014;11:361-2.

24. Blue GM, Ip E, Walker K, Kirk EP, Loughran-Fowlds A, Sholler GF, et al. Genetic burden and associations with adverse neurodevelopment in neonates with congenital heart disease. Am Heart J. 2018;201:33-9.

25. Schieffer KM, Varga E, Miller KE, Agarwal V, Koboldt DC, Brennan P, et al. Expanding the clinical history associated with syndromic Klippel-Feil: a unique case of comorbidity with medulloblastoma. Eur J Med Genet. 2019; 62:103701.

26. Berger J, Berger S, Li M, Currie PD. Myo18b is essential for sarcomere assembly in fast skeletal muscle. Hum Mol Genet. 2017;26:1146-56.

27. Lalli MA, Jang J, Park JH, Wang Y, Guzman E, Zhou H, et al. Haploinsufficiency of BAZ1B contributes to Williams syndrome through transcriptional dysregulation of neurodevelopmental pathways. Hum Mol Genet. 2016;25:1294-306.

28. Shafeghati $Y$, Kniepert A, Vakili G, Zenker M. Fraser syndrome due to homozygosity for a splice site mutation of FREM2. Am J Med Genet Part A. 2008;146a:529-31.

29. Yu Q, Lin B, Xie S, Gao S, Li W, Liu Y, et al. A homozygous mutation p. Arg2167Trp in FREM2 causes isolated cryptophthalmos. Hum Mol Genet. 2018;27:2357-66.

30. Dong C, Umar M, Bartoletti G, Gahankari A, Fidelak L, He F. Expression pattern of Kmt2d in murine craniofacial tissues. Gene Expr Patterns. 2019;34:119060.

31. Roma D, Palma P, Capolino R, Figà-Talamanca L, Diomedi-Camassei F, Lepri FR, et al. Spinal ependymoma in a patient with kabuki syndrome: a case report. BMC Med Genet. 2015;16:80

32. Faundes $V$, Malone $G$, Newman WG, Banka S. A comparative analysis of KMT2D missense variants in kabuki syndrome, cancers and the general population. J Hum Genet. 2019;64:161-70.

33. Samartzis D, Kalluri P, Herman J, Lubicky JP, Shen FH. "clinical triad" findings in pediatric Klippel-Feil patients. Scoliosis Spinal Disord. 2016;11:15.

34. Giampietro PF, Raggio CL, Blank RD, McCarty C, Broeckel U, Pickart MA. Clinical, genetic and environmental factors associated with congenital vertebral malformations. Mol Syndromol. 2013:4:94-105.

35. Rolfe RA, Bezer JH, Kim T, Zaidon AZ, Oyen ML, latridis JC, et al. Abnormal fetal muscle forces result in defects in spinal curvature and alterations in vertebral segmentation and shape. J Orthop Res. 2017;35:2135-44.

36. Wei A, Shen B, Williams LA, Bhargav D, Gulati T, Fang Z, et al. Expression of growth differentiation factor 6 in the human developing fetal spine retreats from vertebral ossifying regions and is restricted to cartilaginous tissues. J Orthop Res. 2016;34:279-89.

37. Dauer MVP, Currie PD, Berger J. Skeletal malformations of Meox1-deficient zebrafish resemble human Klippel-Feil syndrome. J Anat. 2018;233:687-95.

38. Ajima R, Akazawa H, Kodama M, Takeshita F, Otsuka A, Kohno T, et al. Deficiency of Myo18B in mice results in embryonic lethality with cardiac myofibrillar aberrations. Genes Cells. 2008;13:987-99.

39. Mclnerney-Leo AM, Sparrow DB, Harris JE, Gardiner BB, Marshall MS, O'Reilly VC, et al. Compound heterozygous mutations in RIPPLY2 associated with vertebral segmentation defects. Hum Mol Genet. 2015;24:1234-42.

40. Nicolaou N, Pulit SL, Nijman IJ, Monroe GR, Feitz WF, Schreuder MF, et al. Prioritization and burden analysis of rare variants in 208 candidate genes suggest they do not play a major role in CAKUT. Kidney Int. 2016;89:476-86.

41. Clarke CM, Fok VT, Gustafson JA, Smyth MD, Timms AE, Frazar CD, et al. Single suture craniosynostosis: identification of rare variants in genes associated with syndromic forms. Am J Med Genet A. 2018;176:290-300.

42. Singer $G$, Schalamon J, Ainoedhofer H, Petek E, Kroisel PM, Höllwarth ME. Williams-Beuren syndrome associated with caudal regression syndrome and coagulopathy--a case report. J Pediatr Surg. 2005;40:e47-50.

43. Li J, Cui $Y, X u$ J, Wang Q, Yang X, Li Y, et al. Suppressor of fused restraint of hedgehog activity level is critical for osteogenic proliferation and 
differentiation during calvarial bone development. J Biol Chem. 2017;292: 15814-25.

44. De Mori R, Romani M, D'Arrigo S, Zaki MS, Lorefice E, Tardivo S, et al. Hypomorphic recessive variants in SUFU impair the sonic hedgehog pathway and cause Joubert syndrome with Cranio-facial and skeletal defects. Am J Hum Genet. 2017;101:552-63.

45. Pehlivan D, Bayram Y, Gunes N, Coban Akdemir Z, Shukla A, Bierhals T, et al. The genomics of Arthrogryposis, a complex trait: candidate genes and further evidence for Oligogenic inheritance. Am J Hum Genet. 2019;105: $132-50$.

\section{Publisher's Note}

Springer Nature remains neutral with regard to jurisdictional claims in published maps and institutional affiliations.

Ready to submit your research? Choose BMC and benefit from:

- fast, convenient online submission

- thorough peer review by experienced researchers in your field

- rapid publication on acceptance

- support for research data, including large and complex data types

- gold Open Access which fosters wider collaboration and increased citations

- maximum visibility for your research: over $100 \mathrm{M}$ website views per year

At BMC, research is always in progress.

Learn more biomedcentral.com/submissions 